\title{
Should We Really Treat Every Obese Individual?
}

\author{
Manfred J. Müller ${ }^{\mathrm{a}} \quad$ Johannes Hebebrand $^{\mathrm{b}}$ \\ a Institute of Human Nutrition and Food Science, Christian-Albrechts-University Kiel, \\ ${ }^{b}$ Department of Child and Adolescent Psychiatry and Psychotherapy, University of Duisburg-Essen, Essen, Germany
}

Typically guidelines recommend weight loss therapy for patients with a BMI $\geq 30 \mathrm{~kg} / \mathrm{m}^{2}$ and for patients with a BMI $\geq 25$ $\mathrm{kg} / \mathrm{m}^{2}$ who additionally have a high-risk waist circumference and other risk factors (e.g. North American Association for the Study of Obesity (NAASO); [1]). The EASO has recently published a clinical care pathway algorithm which applies to all individuals with a $\mathrm{BMI} \geq 25 \mathrm{~kg} / \mathrm{m}^{2}$ or a high-risk waist circumference [2]. Evidently, such guidelines imply that a substantial proportion of the general population should be targeted. Indeed, there is ample evidence that overweight and obesity have adverse health effects via the elevated predisposition for the development of a host of chronic diseases; obesity is also associated with an elevated mortality [3-5]. The approximate relative risks of physical health problems associated with obesity have been estimated $\geq 3$ for type 2 diabetes mellitus, gallbladder disease, dyslipidemia, insulin resistance, breathlessness, and sleep apnea [6]. Based on such data, overweight and obesity are considered as major health problems suggesting a general need for prevention and treatment $[6,7]$. In this editorial we wish to critically question the general applicability of treatment recommendations to all subjects fulfilling the respective inclusion criteria.

\section{Not Every Overweight/Obese Individual Carries an Elevated Risk for the Development of Obesity Related Chronic Health Problems}

The association between overweight and chronic diseases is unclear because of their multifactorial etiology. For example, although insulin resistance is considered as a common feature of obesity only about $34-60 \%$ of obese patients were insulin resistant based on the methodological gold standard (i.e. an euglycemic hyperinsulinemic clamp protocol) [8]. In addition, a stringent association between body weight and health has been questioned by the epidemiological observation that the incidence of cardiovascular disorders has decreased over time as body weight has risen [9]. This idea is supported by National Health and Nutrition Examination Survey (NHANES) data showing the lowest death rates in overweight subjects when compared to other weight groups [9].

Two recent publications provide further evidence for substantial heterogeneity within obese subjects as to their overweightassociated health risks $[10,11]$. Based on cross-sectional data on 5,440 adult participants of the NHANES 1999-2004, Wildman et al. [10] found that $51.3 \%$ of overweight and $31.7 \%$ of obese adults were metabolically healthy as defined via the absence of cardiometabolic abnormalities, including elevated blood pressure, hyperlipidemia, insulin resistance and elevated serum levels of C-reactive protein. Correlates of no or low risk in overweight and obese subjects were young age, ethnicity, high leisure time physical activity, and a small waist circumference. Vice versa, old age, smoking, and large waist circumference were associated with the metabolically abnormal phenotype.

These data are in line with a clinical study on 314 adult subjects of the Tübingen TULIP (Tübinger Lebensstil Interventions-Programm) cohort [11]. These authors also considered $25.4 \%$ of their obese subjects as metabolically benign. Detailed and careful characterization of subjects (including body composition analyses by MRI, measurement of ectopic fat in liver and muscle by MR spectroscopy, assessment of insulin resistance by an oral glucose load, estimation of aerobic fitness on a cycle ergometer as well as measurements of intima media thickness of the common carotid arteria) were performed to detect metabolic disturbances and early signs of atherosclerosis. When compared with individuals of normal weight, benign obese subjects had normal insulin sensitivity and no differences in intima-media thickness. When compared with obese subjects at high cardiometabolic risk (= non-benign obese individuals), metabolically benign obesity was as-

\section{KARGER}

Fax +497614520714

Information@Karger.de

www.karger.com
(C) 2008 S. Karger GmbH, Freiburg

Accessible online at:

www.karger.com/ofa
Prof. Dr. Manfred James Müller

Institut für Humanernährung und Lebensmittelkunde

Christian-Albrechts-Universität zu Kiel

Düsternbrooker Weg 17, 24105 Kiel, Germany

Tel.: +49 431880 56-70, Fax -79

mmueller@nutrfoodsc.uni-kiel.de 
sociated with a similar BMI, waist circumference, fat mass (FM) and subcutaneous abdominal fat, respectively. The benign obese phenotype had only slightly lower visceral fat mass; however, ectopic fat deposits in muscle and particularly in liver were significantly less. There were no differences in age and aerobic fitness between the two groups of obese subjects. In conclusion, both studies [10.11] suggest that between 25 and $30 \%$ of the obese population do not need either treatment or prevention of secondary disorders. Clearly, the mere knowledge of an elevated risk status should not lead us to lump all overweight individuals together; statistical associations cannot substitute for individual risk factor analyses.

\section{We Need to Diagnostically Differentiate between Healthy and Unhealthy Overweight}

From both a clinical and economical point of view it seems prudent to focus on only those obese who harbor an increased risk for obesity-related health problems. However, identification of this subgroup has to be improved. In epidemiological studies a larger waist circumference has very convincingly been shown to correlate with metabolic risk factors independently of BMI [4, 5]. In addition, the waist-to-height ratio may surpass the waist circumference as a predictor: A recent study based on over 13,000 females revealed that, whereas BMI was most closely related to blood pressure, the waist-to-height ratio correlated more closely with the other risk factors than BMI, waist circumference or waist-to-hip ratio [12]. In contrast with such epidemiological data, no differences in waist circumference and only small differences in MR-determined visceral fat were seen between the benign and non-benign obese populations in the TULIP cohort [11].

In the clinical situation, BMI and waist circumference are routinely used for first classification of the patient. However both estimates may have a limited value for individual risk assessment. Stefan et al. [11] concluded that 'ectopic fat in the liver may be more important than visceral fat in the determination of such a beneficial phenotype in obesity'. However, the clinical evidence for the use of ectopic fat in liver (and/or skeletal muscle) as a diagnostic marker needs to be substantiated. Unfortunately, quantitative estimates of liver fat are currently difficult to reach in daily practice. Perhaps, determinations of plasma fetuin-A levels can serve as a substitute. Fetuin-A is a protein secreted almost exclusively by the liver. Higher levels predict both type 2 diabetes mellitus and cardiovascular disorders $[13,14]$.

To more easily predict those obese patients with an increased cardiometabolic risk, Stefan et al. [11] recommended the determination of the fasting insulin concentration. A value below $7.63 \mu \mathrm{U} / \mathrm{ml}$ predicted belonging to the benign group with a high sensitivity (0.97) and a good specificity (0.88). Despite these convincing data, routine insulin measurements are currently not recommended in obese subjects. Among obese subjects, the prevalence of hyperinsulinemia has been reported to vary between 50 and $80 \%$ [8], thus exceeding clampderived measures of insulin resistance as mentioned above. Unfortunately, family history data (e.g. occurrence of overweight and obesity and associated disorders, age at death of first- and second-degree relatives) were not incorporated into the risk assessment. To what extent the elucidation of polygenes involved in body weight regulation and in obesity -related disorders will prove helpful in the future remains to be determined [15].

\section{Age Aspects Are Important}

A major drawback of the two studies related to the differentiation of benign from non-benign obesity $[10,11]$ is that they are based on cross-sectional data. Thus, it cannot be excluded that some of the benign obese subjects will acquire cardiometabolic risks within the upcoming years. In fact, healthy obese subjects of the NHANES population were about 8 years younger than the obese at increased cardiometabolic risk [10]. By contrast, the two obese groups of the TULIP cohort did not differ in mean age [11]. Nevertheless, increases in BMI, percentage fat mass ( $\%$ FM), waist circumference, systolic blood pressure, HOMA-IR and other metabolic variables are well known to increase with age, except for HDL-C concentrations [16]. Subjects with a metabolic syndrome are generally older and have higher mean BMI,\% FM and waist circumference than those without [16]. A rough calculation revealed that it may take at least 6 years of obesity to become an obese patient.

\section{Associations Do Not Necessarily Hold up over Time and Do Not Automatically Prove Causality}

The analysis of 5 cross-sectional, nationally representative surveys conducted in the USA between the early 1960s and the end of the last century revealed that the prevalence of all cardiovascular risk factors, except type 2 diabetes mellitus, decreased over time across all BMI groups, with the greatest reductions observed among overweight and obese groups [3, 4, 9]. The observation that obese persons now have better risk factor profiles than their leaner counterparts did 20-30 years ago, combined with trend data in the general population, suggest that other factors such as dietary changes and increased physical activity levels, but also better treatment of hyperlipidemia and hypertension, may be compensating for the increases in obesity. We may thus be overestimating the medical risks of overweight as specific associations become weaker over time. It should be emphasized that for some of the known associations between obesity and specific disorders we do not at all have evidence of causal relationships (e.g. specific types of cancer). 


\section{Targeting the Total Obese Population Might Do More Harm than Good}

It is beyond the scope of this editorial to extensively dwell on potential 'side effects' of targeting all obese individuals. Suffice it to point out that the uncritical targeting all obese individuals perpetuates the notion that obesity is bad per se. This medical viewpoint contributes to the stigmatization of obese individuals, which has become extremely prevalent [17]; experiencing this stigmatization may even pose an independent health risk. If we can develop feasible tools to differentiate individuals with benign obesity from non-benign obese individuals, we will be removing some of the burden resting on the obese population.

To conclude, we should not automatically think of obesity as a non-benign condition. We need further research to advance the cardiovascular and metabolic risk assessment of individuals of all weight categories. Obviously, obese individuals will continue to be our patients due to their obesity-associated elevated risk status.

\section{References}

1 NHLBI Obesity Education Initiative: The Practical Guide. Identification, Evaluation, and Treatment of Overweight and Obesity in Adults. www.nhlbi.nih. gov/guidelines/obesity/prctgd_c.pdf.

2 Tsigos C, Hainer V, Basdevant A, Finer N, Fried M, Mathus-Vliegen E, Micic D, Maislos M, Roman G, Schutz Y, Toplak K, Zahorska-Markiewicz B: Management of obesity in adults: European Clinical Practice Guidelines. Obesity Facts 2008;1:106-116.

3 Gregg EW, Cheng YJ, Cadwell BL, Imperatore G, Williams DE, Flegal KM, Narayan KM, Williamson DF: Secular trends in cardiovascular disease risk factors according to body mass index in US adults. JAMA 2005;293:1868-1874.

4 Adams KF, Schatzkin A, Harris TB, Kipnis V, Mouw T, Ballard-Barbash R, Hollenbeck A, Leitzmann MF: Overweight, obesity, and mortality in a large prospective cohort of persons 50 to 71 years old. N Engl J Med 2006;355:763-778.

5 Pischon T, Boeing H, Hoffmann K, et al: Genera and abdominal adiposity and risk of death in $\mathrm{Eu}-$ rope. N Engl J Med 2008:359:2105-2120.

6 World Cancer Research Fund/ American Institute for Cancer Research: Food, Nutrition, Physical Activity and the Prevention of Cancer: a Global Perspective. London, WCRF International, 2007.
7 WHO Technical Report Series 894: Obesity: Preventing and Managing the Global Epidemic. Geneva, WHO, 2000.

${ }_{8}$ Ferrannini E, Natali A, Bell P, Cavallo-Perin P, Lalic N, Mingrone G: Insulin resistance and hypersecretion in obesity. European Group for the Study of Insulin Resistance (EGIR). J Clin Invest 1997; 100:1166-1173.

9 Flegal KM, Graubard BI, Williamson DF, Gail MH: Cause-specific excess deaths associated with underweight, overweight, and obesity. JAMA 2007:298: 2028-2037.

10 Wildman RP, Muntner P, Reynolds K, McGinn A, Rajpathak S, Wylie-Rosett J, Sowers MFR: The obese without cardiometabolic risk factor clustering and the normal weight with cardiometabolic risk factor clustering. Ann Intern Med 2008;168: $1617-1624$.

11 Stefan N, Kantartzis K, Machann J, Schick F, Thamer C, Rittig K, Balletshofer B, Machicao F, Fritsche A, Häring H-U: Identification and characterization of metabolically benign obesity in humans. Ann Intern Med 2008:168:1609-1616.
12 Kwok S, McElduff P, Ashton DW, Lowe GDO, Wood D, Humphries SE, Charlton-Menys V, Durrington PN: Indices of obesity and cardiovascular risk factors in British women. Obesity Facts 2008; 1:190-195.

13 Stefan N, Fritsche A, Weikert C, Boeing H, Joost HG, Häring HU, Schulze MB: Plasma fetuin-A levels and the risk of type 2 diabetes. Diabetes 2008; 57:2762-2767.

14 Weikert C, Stefan N, Schulze MB, Pischon T, Berger K, Joost HG, Häring HU, Boeing H, Fritsche A Plasma fetuin-A levels and the risk of myocardial infarction and ischemic stroke. Circulation 2008. DOI: CIRCULATIONAHA.108.814418.

15 Hinney A, Hebebrand J: Polygenic obesity in humans. Obesity Facts 2008;1:35-42.

16 Bosy-Westphal A, Onur S, Geisler C, Wolf A, Korth O, Pfeuffer M, Schrezenmeir J, Krawczak M, Müller MJ: Common familial influences on clustering of metabolic syndrome traits with central obesity and insulin resistance: the Kiel obesity prevention study. Int J Obes 2007:31:784-790.

17 Puhl RM, Latner JD: Stigma, obesity, and the health of the nation's children. Psychol Bull 2007; 133:557-580. 


\section{On the Contents of This Issue}

Topics covered in the current issue include effects of the fat distribution pattern on glucose metabolism, measurement of body fat, methodological aspects to address potential biases due to non-response in epidemiological studies, molecular genetics, treatment and influences of the diet on future body weight and glucose metabolism. The papers are based on both human and rodent studies.

Does the Atkin diet work for rodents? Mirhashemi et al. (Potsdam, Germany) [1] provided $d b / d b$ mice with a high fat, carbohydrate-free diet. The group had previously shown that this diet prevents diabetes and $\beta$-cell destruction in the New Zealand Obese mouse strain. When kept on a carbohydrate containing standard diet $d b / d b$ mice developed severe diabetes as characterized by blood glucose $>20 \mathrm{mmol} / \mathrm{l}$, weight loss, polydipsia and polyurea; a selective loss of of pancreatic $\beta$-cells, reduced GLUT2 expression in the remaining $\beta$-cells, and reduced plasma insulin levels were observed. In contrast, $d b / d b$ mice kept on a high-fat, carbohydrate-free diet did not develop diabetes and exhibited near-normal, hyperplastic islets in spite of a morbid obesity associated with hyperinsulinemia. The investigators successfully extended their initial observation to a second rodent model; apparently dietary carbohydrates are required for $\beta$-cell destruction.

The difficulties in losing weight are all too well known. Can a more personalized approach help to overcome this major problem inherent to conventional weight loss programs? McDoniel et al. (Minneapolis, MN, USA) [2] report initial promising results based on provision of personalized information with respect to energy intake based on measurement of resting metabolic rate (RMR). 54 overweight (36 males, 18 females; BMI range $25.2-35.6 \mathrm{~kg} / \mathrm{m}^{2}$ ), active duty adult employees of the US Air Force aged 18 to 46 years were included in the 90-day study. Those subjects who were randomly assigned to the experimental group were provided with a hand-held indirect calorimeter; during the four treatment sessions these cases were counseled by dieticians based on the measured RMR and thus received a personalized nutrition energy goal message. They also received a handout delineating factors that influence RMR. The controls were also counseled four times by the dieticians; their advised daily energy intake in kcal was derived from a crude estimate of RMR based on current body weight. Of the 19 cases and 25 controls, who completed the study, cases lost significantly more weight $(-4.3 \pm 3.3 \mathrm{~kg}$ vs. $-1.8 \pm$ $3.2 \mathrm{~kg})$.

Genes coding for proteins of the endocannabinoid system represent candidate genes for obesity. Durand et al. (Lille, France) [3] genotyped 635 obese children, 896 morbidly obese adults, 2,238 subjects with type 2 diabetes mellitus
(T2DM) and 1,340 controls of French European origin for 10 tagging single nucleotide polymorphisms (SNPs) within the fatty acid amide hydrolase (FAAH), which inactivates the most important endocannabinoid ligand, anandamide, and hydrolyses other long fatty acids that bind to the endocannabinoid receptors. Nominal evidence of association was observed for six SNPs, including Pro129Thr, with class III adult obesity; no associations were observed to childhood obesity and T2DM. Because the findings were not significant upon correction for multiple testing, the investigators recommend further studies of this interesting candidate gene.

It has been suggested that peripheral adipose tissue may protect against some of the negative effects of central adiposity. Simple anthropometric measurements have commonly served as surrogate markers of fat localization; however, they cannot differentiate subcutaneous adipose tissue from visceral depots. To gain more insight into the relationship between different thigh adipose tissue compartments (subcutaneous and intrafascial (deep)) and glucose metabolism, Pigeon et al. (Quebec, Canada) [4] performed midthigh and abdominal computed tomography (CT) scans in 63 men and 110 women from the Quebec Family Study. Areas and attenuations of adipose tissue compartments and skeletal muscle measured from CT scans were related to glycemia and insulinemia values from an oral glucose tolerance test (OGTT). Upon appropriate adjustments negative relationships ( $\mathrm{r}$ values from -0.2 to -0.3 ) between the surface area of mid-thigh subcutaneous adipose tissue (SCAT) and OGTT data were observed; upon correction for visceral adiposity similar albeit weaker correlations applied. The results suggest that mid-thigh SCAT is protective of the development of glucose intolerance.

Bosy-Westphal et al. (Kiel, Germany) [5] compared body composition determined by four bioelectrical impedance (BIA) consumer devices (3 single-frequency bipedal and 1 tetrapolar) against criterion estimates determined by whole-body magnetic resonance imaging (MRI) and dual energy X-ray absorptiometry (DXA) in 106 subjects of different weight categories. Based on the respective correlations, the investigators conclude that because of the lower agreement between foot-to-foot BIA and DXA or MRI, tetrapolar electrode arrangement should be preferred for individual or public use. Bipolar devices were judged as providing accurate results for field studies focusing on group estimations.

In a second study of the Kiel group, Plachta-Danielzik et al. [6] address two important questions relevant to epidemiological studies: How representative is a subgroup of participants who respond to a specific questionnaire in relationship to the whole study group? What methods should be used to control for response bias? The total study group of 
the investigators was derived from the Kiel Obesity Prevention Study and encompassed a total of 4,997 cross-sectional data of 5- to 7-year-old German children who were investigated between 1996 and 2001 upon school entry examination. Parents of a subgroup of 2,631 of these probands responded to a questionnaire related to socio-demographic and lifestyle factors. To control for response bias a non-response analysis as well as an analysis of missing values were performed. The responders were characterized by a lower prevalence of obese boys and girls from families of low socio-economic status. The analysis of missing values did not detect any further biases. The investigators concluded that the analysis of non-response is the most sensitive method to detect group differences, but a comparison with the total population can also be used to control for biases. Representativity has to be proven not only for the main cohort but also for the subgroup of responders subjected to data analysis.

Iqbal Kring and Heitman (Copenhagen, Denmark) [7] assessed the influence of dietary energy density at baseline on body weights of 398 8- to 10 -year-old boys and girls who were followed up 3 years later. Validated 24-hour recall interviews were used to determine dietary energy intake at baseline. Multiple regression analyses were performed using both anthropometric and dietary data. Dietary energy density was not associated with 3-year weight gain in girls and boys. Only energy and fiber intakes were related to weight gain, but in different ways for subgroups of normalweight and overweight boys. Limitations of the study include a relatively small sample size and the fact that only a single 24-hour dietary recall interview was collected for each individual, which may be considered as insufficient to characterize the usual energy intake. Previous studies of this kind have come up with mixed results. Based on their results the authors critically reflect on the WHO recommendation to reduce energy density as a measure to prevent weight gain.

This last issue of 2008 marks the completion of the first year of OBEsITy FACTS. We wish our readers a Merry Christmas and a Happy New Year!

\section{References}

1 Mirhashemi F, Kluth O, Scherneck S, Vogel H, Kluge R, Schürmann A, Joost H-G, Neschen S: High-fat, carbohydrate-free diet markedly aggravates obesity but prevents beta cell loss and diabetes in the obese, diabetes-susceptible $d b / d b$ strain. Obesity Facts 2008;1(6):292-297.

2 McDoniel SO, Nelson HA, Thomson CA: Employing RMR technology in a 90-day weight control program. Obesity Facts 2008;1(6):298-304.

3 Durand E, Lecoeur C, Delplanque J, Bezinou M, Degraeve F, Boutin P, Marre M,. Balkau B, Charpentier G, Froguel P, Meyre D: Evaluating the association of FAAH common gene variation with childhood, adult severe obesity and type 2 diabetes in the French population. Obesity Facts 2008;1(6):305-309.

4 Pigeon É, Couillard É, Tremblay A, Bouchard C, Weisnagel J, Joanisse DR: Mid-thigh subcutaneous adipose tissue and glucose tolerance in the Quebec Family Study. Obesity Facts 2008;1(6):310-318.

5 Bosy-Westphal A, Later W, Hitze B, Sato T, Kossel E, Glüer C-C, Heller M, Müller MJ: Accuracy of BIA consumer devices for measurement of body composition in comparison to whole body magnetic resonance imaging and dual X-ray absorptiometry. Obesity Facts 2008;1(6):319-324.

6 Plachta-Danielzik S, Bartel C, Raspe H, Thyen U, Müller MJ: Assessment of representativity of a study population - experience of the Kiel Obesity Prevention Study (KOPS). Obesity Facts 2008;1(6):325-330.

7 Iqbal Kring S, Heitmann BL: Fiber intake, not dietary energy density, is associated with subsequent change in BMI z-score among sub-groups of children. Obesity Facts 2008;1(6):331-338. 